\title{
Congenital Heart Disease Characteristics in Low Birth Weight Infants at Dr. Hasan Sadikin General Hospital in 2010-2014
}

\author{
Villia Damayantie, ${ }^{1}$ Sri Endah Rahayuningsih, ${ }^{2}$ Irvan Afriandi ${ }^{3}$ \\ ${ }^{1}$ Faculty of Medicine Universitas Padjadjaran, Indonesia, ${ }^{2}$ Department of Child Health Faculty \\ of Medicine Universitas Padjadjaran/Dr. Hasan Sadikin General Hospital Bandung, Indonesia, \\ ${ }^{3}$ Department of Public Health Faculty of Medicine Universitas Padjadjaran, Indonesia
}

\section{Abstract}

Background: Congenital heart disease (CHD) is a multifactorial disease defined as an anomaly in the macroscopic structure of the heart that may cause functional disorders. The incidence of CHD is reported higher in infants with low birth weight (LBW) than the entire population of neonates. This study aimed to describe the characteristics of CHD in infants born with LBW.

Methods: This was a retrospective descriptive study with a cross-sectional design, performed in October-November 2015. Data were obtained from medical records of inpatients infants at Dr. Hasan Sadikin General Hospital, Bandung in the period of 2010-2014. The data presented were the characteristics of CHD in LBW infants.

Results: Of 364 LBW infants treated in the hospital within 5 years period, 21 infants (14 girls and 7 boys) were diagnosed as CHD, with birth weight group predominantly (n18; 85.7\%) in the range of 1,500-2,499 gr. Non-cyanosis CHD was prevalent in 95.2\% (n20),and patent ductus arteriosus (PDA) was found in $76.1 \%$ (n16). Comorbid conditions mostly found in this study were preterm birth (n17), sepsis (n10), and neonatal hyperbilirubinemia (n9).

Conclusions: The most common type of CHD in low birth weight infants in Dr. Hasan Sadikin General Hospital is Patent Ductus Arteriosus. The presence of congenital heart disease should be considered in low birth weight infants, thus it is essential to perform screening for early recognition.

Keywords: Congenital heart disease, infants, low birth weight

\section{Introduction}

Congenital heart disease (CHD) accounts for nearly one-third of all major congenital anomaly and is known as one of the main causes of death in the first year of life. Congenital heart disease is defined as an anomaly in the macroscopic structure of the heart or the large blood vessel, which can cause functional disorders. ${ }^{1}$ Most causes of CHD are multi-factorial, which are a combination of genetic predisposition and environmental stimuli. Some CHD cases are associated with chromosomal abnormality. ${ }^{2}$ The other risk factors include maternal comorbidities, family history of CHD, being born as the first child, medications taken during the pregnancy, and the age of the mother. ${ }^{3}$ The incidence of CHD worldwide varies from year to year, with the estimation of 8 out of $1,000(0.8 \%)$ live births. Several studies show that the incidence of CHD is more common in infants with low birth weight (LBW) than in the entire neonate population. ${ }^{4-6}$ Low birth weight is defined as birth weight less than 2,500 grams. The incidence of LBW infants is about 20.6 million and it accounted for $15.5 \%$ of all births globally and $95.6 \%$ has occurred in the developing countries. In Indonesia ${ }^{7}$, the prevalence of LBW infants is $10.2 \%$, and 902 cases are found in Bandung, West Java.

A study conducted in Korea ${ }^{5}$ shows that the highest incidence of CHD has been found in a subgroup of infants born with 1,000-2,500 grams of birth weight, which is $9.3 \%$ of the entire population. The most common type of lesions is ventricular septal defect (VSD), which comprises $48.9 \%$ of the total 7,245

Correspondence: Villia Damayantie, Faculty of Medicine, Universitas Padjadjaran, Jalan Raya Bandung-Sumedang Km.21, Jatinangor, Sumedang, Indonesia, Email: villia.damayantie@yahoo.co.id 
cases. $^{6}$ Lesions of CHD can lead to LBW due to the presence of hemodynamic disorders. Moreover, CHD in LBW infants may present with other comorbid conditions and could increase infant morbidity and mortality. ${ }^{8-13}$

In Indonesia, there are not many studies describing CHD in LBW infants, especially in West Java. This study aimed to describe the characteristics of CHD in infants born with LBW.

\section{Methods}

A descriptive method with cross-sectional research design was conducted. Data collections were obtained from medical records of hospitalized patients with CHD in infants born with LBW within 5-year, from January 2010 until December 2014. Data were taken from October to November 2015 from the Medical Records Installation of the inpatients of the Perinatology Room at Dr. Hasan Sadikin General Hospital. The study was approved by the Health Research Ethics Committee of Dr. Hasan Sadikin General Hospital.
All data of newborn infants aged up to 28 days with LBW who were admitted in the Perinatology Room at Dr. Hasan Sadikin General Hospital were collected (n 364). The inclusion criteria of this study were complete medical records of LBW infants aged 0-28 days with CHD diagnosed through an echocardiography examination.

The selected data were categorized into four groups consisting of the infant characteristics, mother characteristics, type of CHD lesion that was classified into cyanosis and noncyanosis types of lesion, and comorbidity. In the infant characteristic category, the selected data included gender, birth weight, birthplace, and the 10-point Apgar score. Data on birth weight was categorized based on birth weight group of 1,500-2,499 grams, 1,000-1,499 grams, and $<1,000$ grams. The Apgar score was divided into three categories, with 7-10 points categorized as excellent condition, 4-6 points as moderately depressed, and 1-3 points as severely depressed. ${ }^{12}$ In the mother characteristic category, the selected data included mother parity, gestational age,

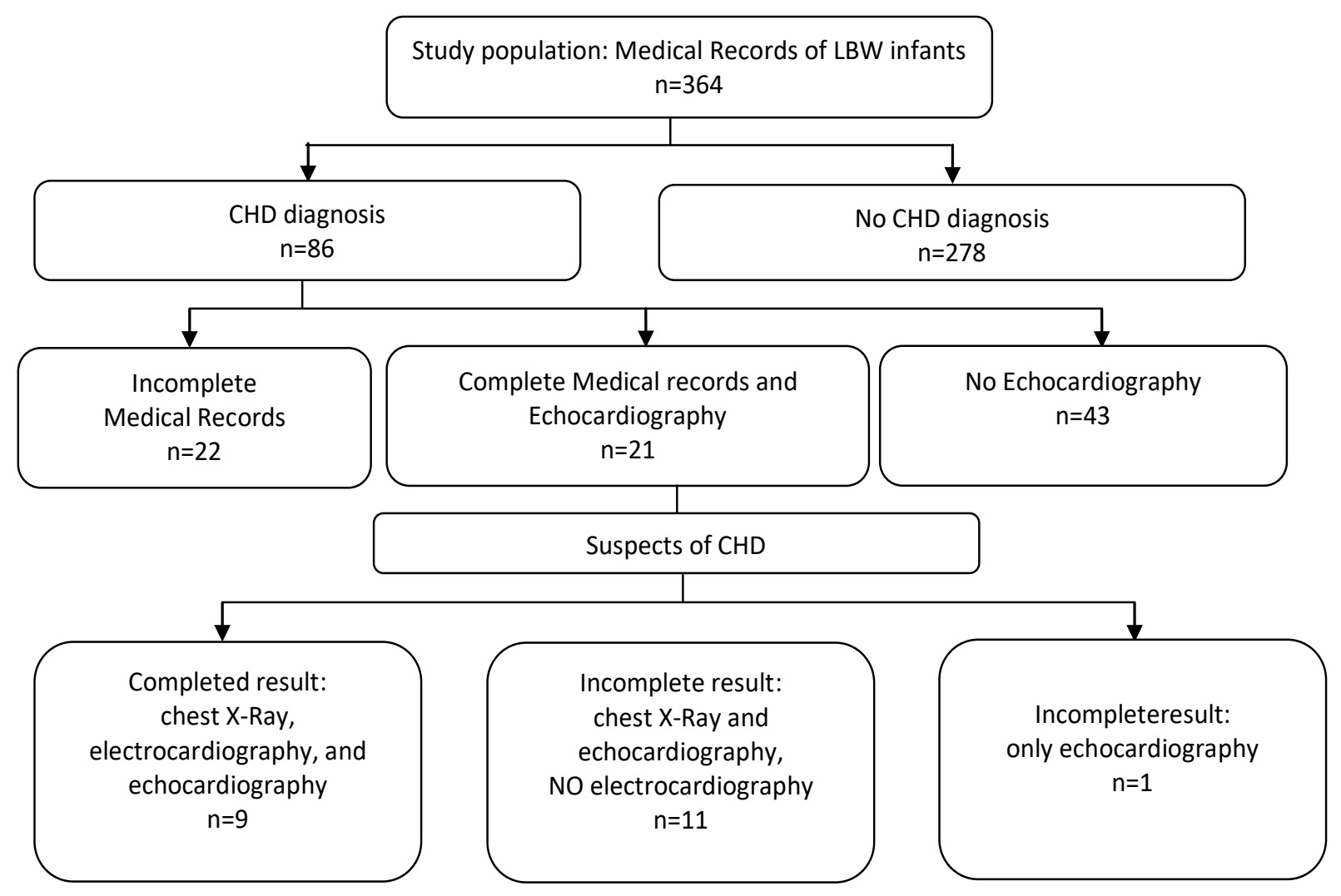

Figure 1 Flowchart Data Collection 
Table 1 Distribution of Birth Weight Groups-for-Gender of Infants

\begin{tabular}{lccc}
\hline \multicolumn{1}{c}{ Birth Weight Groups } & \multicolumn{2}{c}{ Gender } & Total \\
\cline { 2 - 4 } (n)
\end{tabular}

frequency of antenatal care (ANC) visit, and medication history during the pregnancy. Gestational age was divided into pre-term for $<37$ weeks gestational age, a term for $37-42$ weeks gestational age, and post-term for $>42$ weeks gestational age. The frequency of ANC visitwas divided into less than four times, and four times or more. In the type of CHD lesion category, the selected data included the type of lesion, both the cyanosis and non-cyanosis, and the presence of supporting exam results including chest X-ray, electrocardiography (ECG), and echocardiography. In the comorbidity condition category, the selected data included other diseases and other congenital abnormalities in the infants. The data were analyzed and presented in tables.

\section{Results}

There were 21 data obtained from 364 infants with LBW. Other 343 medical record data were excluded consecutively, 278 of them did not contain any CHD diagnosis, 22 of them were lost, and 43 of them were excluded because CHD was not confirmed through the echocardiography examination step. Data were included, only if CHD was confirmed by echocardiography (Figure 1).

In this study, 11 out of 21 samples were born in the hospital and the rest of 10 samples were born assisted by midwives. There were
14 female infants and 7 male infants (Table 1 ). In the birth weight group, the highest frequency was in those born with a birth weight of 1,500-2,499 grams and there was no infant born with a birth weight $<1,000$ grams found in this study.

The results of 1-Minute Apgar scores in this study were mostly found in the excellent category, however, there were 11 samples whose results of 1-minute Apgar scores were not recorded in their medical records (Table $2)$. The results of 5-Minute Apgarscores in this study were mostly found in the excellent category, yet, there were 12 samples whose results of 5-minute Apgar scores were not recorded in their medical records. The results in 10-Minute Apgar scores in this study were mostly found in the excellent category(three samples). Meanwhile, there were 17 samples whose results of 10-minute Apgar scores were not recorded in their medical records.

As shown in Table 3, the highest frequency of parity status was multiparity mothers. Most of the mothers delivered the baby in the gestational age of fewer than 37 weeks and most of them had ANC visit frequency less than 4 times. Unfortunately, only 6 of 21 mothers took vitamins such as iron and calcium tablets given by midwives or doctors at each ANC visit. Interestingly, only one mother received TT immunization during pregnancy of which there were 6 mothers with the first pregnancy.

Table 2 Distribution of Apgar Scoresof Infants with Low Birth Weight $(n=21)$

\begin{tabular}{lccc}
\hline \multicolumn{1}{c}{ Apgar Scores } & $\begin{array}{c}\text { 1-Minute } \\
\text { Total (n) }\end{array}$ & $\begin{array}{c}\text { 5-Minute } \\
\text { Total (n) }\end{array}$ & $\begin{array}{c}\text { 10-Minute } \\
\text { Total (n) }\end{array}$ \\
\hline Severely depressed & 2 & 1 & - \\
Moderately depressed & 2 & 2 & 1 \\
Excellent condition & 6 & 6 & 3 \\
Without Information & 11 & 12 & 17 \\
\hline Notes: 10-points APGAR score designated as Severely depressed: 1-3 points; Moderately depressed: 4-6 points; \\
$\quad$ Excellent condition: 7-10 points
\end{tabular}


Table 3 The distribution of Characteristic from Maternal Factors

\begin{tabular}{|c|c|}
\hline Maternal Factors & Total (n) \\
\hline \multicolumn{2}{|l|}{ Parity } \\
\hline Primiparous & 6 \\
\hline Multiparous & 14 \\
\hline Grandmultiparous & 1 \\
\hline \multicolumn{2}{|l|}{ Gestational Age } \\
\hline Preterm birth & 17 \\
\hline Aterm birth & 4 \\
\hline Post-term birth & - \\
\hline \multicolumn{2}{|l|}{ Frequency of Antenatal Care Visits } \\
\hline$<4$ times & 12 \\
\hline$\geq 4$ times & 9 \\
\hline \multicolumn{2}{|l|}{ Medication History During Pregnancy } \\
\hline Herbal Medicine & - \\
\hline Supplement & 6 \\
\hline Drugs for hypertension mother & 2 \\
\hline TT Immunization & 1 \\
\hline Without Information & 12 \\
\hline
\end{tabular}

Note: Preterm birth: <37 weeks; Aterm birth: 37-42 weeks; Post-term birth: >42 weeks. TT, tetanus toxoid

However, 12 out of 21 samples did not record the history of medication during pregnancy in their medical records.

The highest frequency of CHD lesion in this study was non-cyanosis with patent ductus arteriosus (PDA) and found in 16 out of 21 samples (Table 4). Interestingly five out of 21 infants had more than one lesion whichwas PDA with a patent foramen ovale (PFO).

The number of infants who were born with CHD lesion might be comorbid by the presence of other congenital abnormalities, such as Down syndrome and Labiognatapalatoschizis. However, most of them had no other

Table 4 The Distribution of Type Lesions of Congenital Heart Disease(CHD)

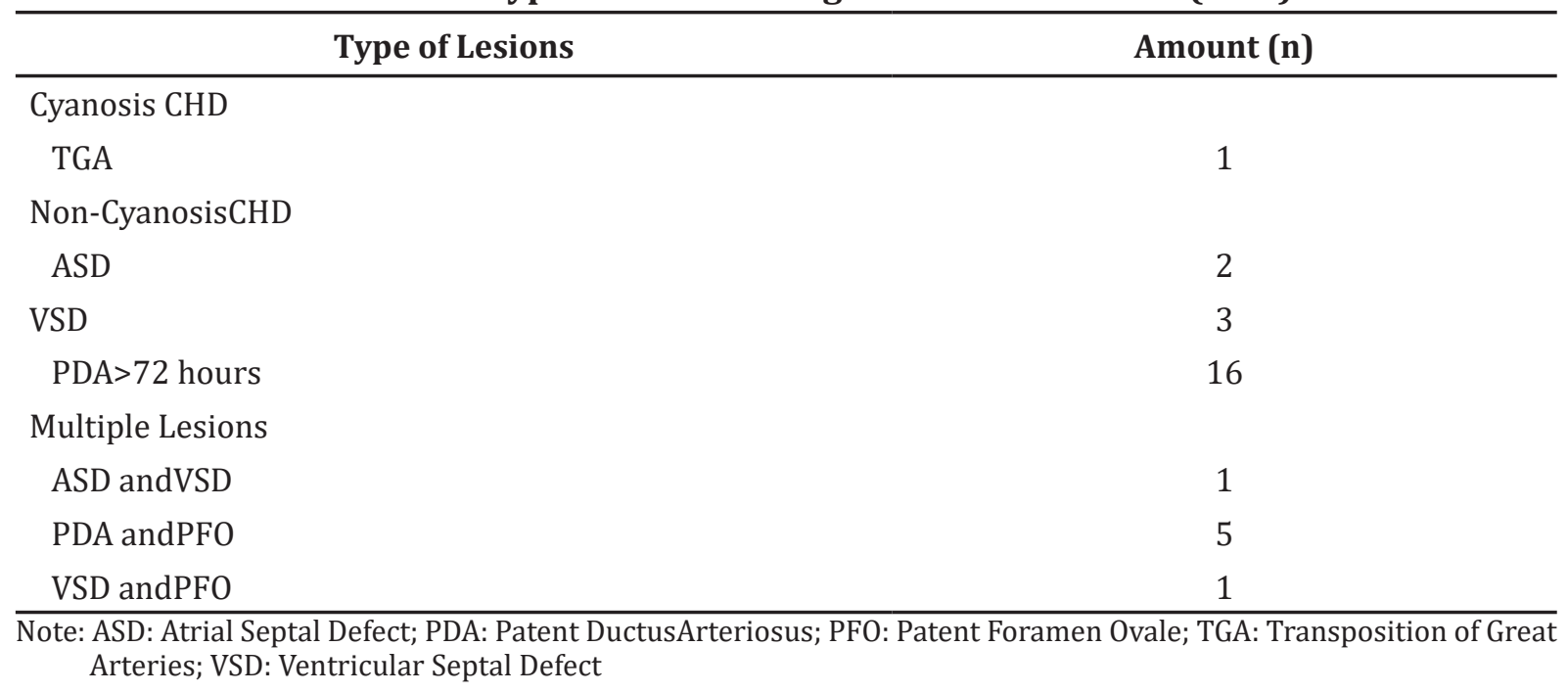


Table 5 Distribution of Comorbidity

\begin{tabular}{|c|c|}
\hline Comorbidity & Total (n) \\
\hline \multicolumn{2}{|l|}{ Other Congenital Abnormalities } \\
\hline Down Syndrome & 2 \\
\hline Congenital Hypothyroid & 1 \\
\hline Hirschsprung Disease & 1 \\
\hline Labiognatapalatoschizis & 2 \\
\hline Without any congenital disorder & 16 \\
\hline \multicolumn{2}{|l|}{ Other Diseases/Conditions } \\
\hline Preterm Infants & 17 \\
\hline Sepsis & 10 \\
\hline Neonatal Hyperbilirubinemia & 9 \\
\hline Omphalitis & 5 \\
\hline Pneumonia & 5 \\
\hline Anemia & 4 \\
\hline Respiratory Distress Syndrome & 4 \\
\hline Thrombocytopenia & 4 \\
\hline Hypoglycemia & 3 \\
\hline Small Gestational Age & 3 \\
\hline Apneu of Prematurity & 2 \\
\hline Asphyxia & 2 \\
\hline G6PD Deficiency & 2 \\
\hline Dehydration & 2 \\
\hline Hypernatremia & 2 \\
\hline Hyponatremia & 2 \\
\hline Bacterial Infection & 2 \\
\hline TORCH Infection & 2 \\
\hline Feeding Problem & 2 \\
\hline Bilirubin Encephalopathy & 1 \\
\hline Hyperkalemia & 1 \\
\hline Hypercalcemia & 1 \\
\hline IUGR & 1 \\
\hline Conjunctivitis & 1 \\
\hline Prolonged aPTT & 1 \\
\hline Phlebitis Dorsum Magnus & 1 \\
\hline Transient Tachypnea of Newborn & 1 \\
\hline
\end{tabular}


accompanied congenital abnormalities. The most comorbid condition found in this study was preterm birth (17 out of 21) followed by sepsis and neonatal hyperbilirubinemia (Table 5).

\section{Discussion}

This study describes an overview of therapeutic Congenital heart disease is generally caused by a fetal development disorder or structural failure in the embryogenesis process. ${ }^{14}$ The incidence of CHD worldwide varies from year to year, with the estimation of 8 out of 1,000 $(0.8 \%)$ live births. ${ }^{1,14}$ Congenital heart disease incidence in infants with LBW is found at a higher rate. Several studies have reported that infants with CHD are at higher risk of having small gestational age (SGA) condition which is closely related to LBW. ${ }^{4,5}$ This study found that 21 out of 364 LBW infants were born with CHD resulting in an incidence of $5.7 \%$ (Figure 1 ). The study result showed that the CHD cases with LBW were predominantly in female infants (Table 1). This is consistent with a study, describing that the frequency of female infants is found higher than the male infants. ${ }^{6}$

Low birth weight defined as an infant with birth weightless than 2,500 grams..$^{15}$ In Indonesia, according to the result of Basic Health Research (Riset Kesehatan Dasar, RISKESDAS) in 2013, the prevalence of infants born with LBW is $10.2 \% .^{7}$ On the other hand, 902 infants are born with LBW in Bandung, West Java, while there are 438 infants born with LBW in Bandung Regency. ${ }^{16}$ Low birth weight is divided into three categories, referred as LBW for a birth weight ranging from 1,5002,499 grams, very low birth weight (VLBW) for birth weight ranging from 1,000-1,499 grams, and extremely low birth weight (ELBW) for birth weight ranging from less than 1,000 grams. However, in this study, all categories were generally referred to as LBW. The study showed that CHD infants were mostly found in the birth weight range of 1,500-2,499 grams, which were 18 out of 21 samples (Table 1). A study conducted in Korea $^{5}$ showed that when patients were being categorized based on their birth weight $(\geq 2,500$ grams, 1,000 2,500 grams, and $<1,000$ grams), the highest CHD incidence was found in the birth weight subgroup of 1,000-2,500 grams, comprising of $9.3 \%(\mathrm{p}<0.001)$, compared to the other two groups, thus the incidenceswere found higher in the LBW group than non-LBW. ${ }^{5}$

The birth of an infant with LBW occurs in those who are preterm birth or having intrauterine growth restriction..$^{15}$ This concept is parallel to thestudy result that showedmost of the infants were born at $<37$ weeks of gestational age (Table 3). Moreover, the result showed someinfants had intrauterine growth restriction (IUGR) as a comorbid condition (Table 5).

Several other factors affecting LBW include maternal factors, infant factors, and socioeconomic conditions. The relationship of mother characteristics and the incidence of LBW indicated significant relationships among pregnancy check-up of ANC, the number of parity, the interval between pregnancies of $<12$ months, mother weight gain, and bad obstetric history ${ }^{17}$ Our study showed that the highest frequency of CHD infants with LBW was found in mothers who had more than one delivery, or multiparity (Table 3). Although other studies stated that the risk of infants born with LBW is threefold higher in those of primiparity than multiparity mother. ${ }^{17}$ The result of ANC visits in this study was similar compared to other studies, that mothers with less frequency of ANC visits have almost six times higher risk of having an LBW baby in comparison to mothers who have 5 or more ANC visits. The frequency of ANC visits is essential healthcare maintenance for pregnant women. During ANC nutritional status of the mother will be assessed, such a condition can also affect fetal nutrition. Early detection of congenital anomaly can be assessed through fetal monitoring during ANC visits. Thus, the less frequent mother received ANC, the risk of having infants LBW and/or any other anomaly condition will be higher. ${ }^{17}$

Since CHD is a multifactorial disease, a combination of genetic predisposition and exogenous factors such as maternal, gestational, and environmental conditions need to be considered. Some of CHD cases are also associated with chromosome abnormality, especially trisomy $21,13,18$, and Turner syndrome. ${ }^{2}$ Several studies mentioned that the most common congenital disorder is Down Syndrome, ${ }^{3,18}$ in line with the result of this study that the most common comorbid congenital disorder is Down Syndrome and Labiognatapalatoschizis (Table 5). However, most of them are not accompanied by other congenital disorder.

Other risk factors include maternal comorbidities, family history of the disease, being born as the first child, medication taken during pregnancy, age of the mother, and gender of the infant. ${ }^{3}$ In this study, two mothers took hypertension and heart disease 
medication during pregnancy (Table 3). A study showed that hypertension drugs may increase the risk of preterm birth, SGA, and infants suffering from an abnormality of cardiovascular system. ${ }^{19}$

Congenital heart disease is generally divided into two classes, the cyanosis, and noncyanosis. The cyanosis is characterized by the presence of central cyanosis due to the rightto-left shunts. Some of the lesions are tetralogy of Fallot, transposition of the great arteries (TGA), and tricuspid atresia. While noncyanosis CHD is characterized by the presence of cardiac septum defect and followed by leftto-right shunts, including VSD, ASD, or patency of some blood vessels that are supposed to be closed as in PDA. Furthermore, non-cyanosis CHD can also be found in an obstruction of the outflow tract of the ventricle like aortic valve stenosis, pulmonary valve stenosis, and coarctation of the aorta. ${ }^{2,20}$ Non-cyanosis was the most frequent type of lesion found in this study, in a ratio of 20:1 with the cyanosis one (Table 4).The most common lesion found in this study was PDA, 16 out of 21 samples, while TGA had the lowest frequency because it was only found in one out of 21 samples. Some of the previous studies usually excluded the PDA lesion due to prematurity which appears during $<72$ hours in infants who are born preterm. Meanwhile, in this study, samples with PDA were diagnosed in $>72$ hours in spite of their prematurity.

The diagnosis of congenital heart disease is based on anamnesis to see the risk factors and disease history, physical examination to determine the presence/absence of cyanosis and examination of heart sound and murmurs, and other supporting examinations. Basic supporting examinations for CHD is chest X-ray to see if there are any enlargement of the heart and vascular marking, electrocardiography (ECG) to see if cardiomegaly or any deviation is found in patients, and routine laboratory tests. Further supporting examinations are also conducted in the form of echocardiography and cardiac catheterization to confirm a CHD diagnosis. The combination of both examinations allow diagnosis for approaching one hundred percent of accuracy. ${ }^{2}$

Congenital heart disease lesion results in infants born with LBW due to hemodynamic disorders. This hemodynamic disorder can lead to increased metabolism, which consequently increases the energy consumption. A CHD infant cannot fulfill this increased energy consumption because he/she suffers from calorie intake impairment. This impairment is presumably caused by the inability of the body to use nutrition for metabolism due to malabsorption and asphyxia. Eventually, a manifestation will appear in the form of LBW and other comorbid conditions thatcontributed to the worsening state of the infants (Table 5). ${ }^{8}$ Many infants require corrective or palliative surgery and hospitalization during the first year of life. Results of the surgery depend on the complexity of the lesions and infant characteristics such as lung development, prematurity, and body weight. ${ }^{4,13}$ Compared to infants born with normal weight, LBW infants with CHD who have undergone surgery are at higher risk of mortality and morbidity. ${ }^{11,13}$

Factors associated with CHD infant morbidity include LBW, prematurity and other conditions such as comorbid diseases. This study showed that the most common comorbid condition was preterm birth, followed by neonate sepsis. Moreover, there were metabolic disorders found, such as neonate hyperbilirubinemia, followed by pneumonia, umbilical cord infection, respiratory distress syndrome (RDS) and abnormality in blood systems such as anemia and thrombocytopenia.

The factors affecting mortality include a birth weight that is less than 1,500 grams, the current low body weight before surgery, and the Apgar score. Generally, the Apgar score is used to determine the level of asphyxia or how much apatient can lose the oxygen level in his/her circulation. These factors may determine the prognosis of a baby born with LBW and diagnosed CHD. ${ }^{12}$ The Apgar score in this study mostly belonged in a good category (Table 2). However, some Apgar score data were not recorded in the medical records, as the reasons were stated in the result part. As the Apgar score worsens, so did the infant prognosis, and it was marked by the increase in the morbidity and even mortality.

This study has several limitations; the study was carried out as a small regional study which may not reflect the actual number of the population. Therefore, research with a large number of samples is recommended. There were also missing and incomplete medical records data. Due to this, data collection from inpatients that were born or admitted should be more organized. Some Apgar scores were not recorded in the medical records due to two reasons; first, there were 10 deliveries handled by midwives and they did not perform the Apgar test post-delivery to the infants. Second, 
several samples already had excellent1-Minute Apgar score, thus, no further assessment was needed.

In conclusion, the most common type of CHD in low birth weight infants in Dr. Hasan Sadikin General Hospital is Patent Ductus Arteriosus. The presence of congenital heart disease should be considered in low birth weight infants; thus, screening is essential for early recognition.

\section{References}

1. Van der Linde D, Konings EE, Slager MA, Witsenburg M, Helbing WA, Takkenberg JJ, et al. Birth prevalence of congenital heart disease worldwide: A systematic review and meta-analysis. J Am Coll Cardiol. 2011;58(21):2241-7.

2. Setty HSSN, Patil SSG, Ramegowda RT, Vijaykumar, Vijayalakshmi IB, Manjunath CN. Comprehensive approach to congenital heart defects. J Cardiovasc Disease Res. 2017;8(1):1-5.

3. Ul Haq F, Jalil F, Hashmi S, Jumani MI, Imdad A, Jabeen M, et al. Risk factors predisposing to congenital heart defects. Ann Pediatr Cardiol. 2011;4(2):117-21.

4. Malik S, Cleves MA, Zhao W, Correa A, Hobbs CA. Association between congenital heart defects and small for gestational age. Pediatrics. 2007;119(4):e976-82.

5. Cho SY, Oh J-H, Lee JH, Lee JY, Lee SJ, Han JW, et al. Recent incidence of congenital heart disease in neonatal care unit of secondary medical center: A single center study. Korean J Pediatr. 2012;55(7):232-7.

6. Lindinger A, Schwedler G, Hense HW. Prevalence of congenital heart defects in newborns in Germany: Results of the first registration year of the pan study (July 2006 to June 2007). Klin Padiatr. 2010;222(5):321-6.

7. Badan Penelitian dan Pengembangan Kesehatan Kementerian Kesehatan Republik Indonesia. Riset kesehatan dasar. Jakarta: Badan Penelitian dan Pengembangan Kesehatan Kementerian Kesehatan Republik Indonesia; 2013.

8. Hagau N, Culcitchi C. Nutritional support in children with congenital heart disease. Nutr Ther Metabol. 2010;28(4):172-84

9. Maramis PP, Kaunang ED, Rompis J. Hubungan penyakit jantung bawaan dengan status gizi pada anak di RSUP Prof. Dr. Rd Kandou Manado tahun 2009-2013. eCl. 2014;2(2):1-8.

10. Alam A, Sukadi A, Risan NA, Dhamayanti M. Preterm and low birth weight as risk factors for infant delayed development. Paediatr Indones. 2008;48(1):1-4.

11. Ades AM, Dominguez TE, Nicolson SC, Gaynor JW, Spray TL, Wernovsky G, et al. Morbidity and mortality after surgery for congenital cardiac disease in the infant born with low weight. Cardiology in the Young. 2010;20(1):8-17.

12. Dimmick S, Walker K, Badawi N, Halliday R, Cooper SG, Nicholson IA, et al. Outcomes following surgery for congenital heart disease in low-birthweight infants. J Paediatr Child Health. 2007;43(5):370-5.

13. Lechner E, Wiesinger-Eidenberger G, Weissensteiner M, Hofer A, Tulzer G, Sames-Dolzer E, et al. Open-heart surgery in premature and lowbirthweight infants-a single-centre experience. Eur J Cardiothorac Surg. 2009;36(6):986-91.

14. Bernier PL, Stefanescu A, Samoukovic G, Tchervenkov CI. The challenge of congenital heart disease worldwide: Epidemiologic and demographic facts. Semin Thorac Cardiovasc Surg Pediatr Card Surg Annu 2010;13(1):26-34.

15. Goldenberg RL, Culhane JF. Low birth weight in the United States. Am J Clin Nutr. 2007;85(2):584S-90S.

16. Departemen Kesehatan Provinsi Jawa Barat. Profil kesehatan Provinsi Jawa Barat tahun 2012. Bandung: Departemen Kesehatan Provinsi Jawa Barat;2012.

17. Negi K, Kandpal S, Kukreti M. Epidemiological factors affecting low birth weight. JK Science. 2006;8(1):31-4

18. Freeman SB, Bean LH, Allen EG, Tinker SW, Locke AE, Druschel C, et al. Ethnicity, sex, and the incidence of congenital heart defects: A report from the national down syndrome project. Genet Med. 2008;10(3):173-80.

19. Lennestål R, Olausson PO, Källén B. Maternal use of antihypertensive drugs in early pregnancy and delivery outcome, notably the presence of congenital heart defects in the infants. Eur J Clin Pharmacol. 2009;65(6):615-25.

20. Meberg A. Congenital heart defects through 30 years. OJPed. 2012;2(3):219-227. 